\title{
PEMBEKALAN METOdE PENGAJARAN IMLA' BAGI PENGAJAR BIMBINGAN MASUK GONTOR YOGYAKARTA
}

\author{
Syaifullahil Maslul| ${ }^{1}$, Muhammad Amin Khizbullah ${ }^{2}$, Thonthowi ${ }^{3}$, Fajar Fithroni ${ }^{4}$ Apriani \\ Novitasari ${ }^{5}$ \\ 1,2UIN Sunan Kalijaga, Yogyakarta, Indonesia \\ ${ }^{3}$ Universitas Ahmad Dahlan, Yogyakarta, Indonesia \\ ${ }^{4}$ Universitas Negeri Yogyakarta, Yogyakarta, Indonesia \\ ${ }^{5}$ SD Islam Al azhar 31 Yogyakarta \\ email: syaifullahil.maslul@uin-suka.ac.id
}

(Diterima: 17 September 2021; Direvisi: 27 September 2021; Dipublikasikan: November 2021)

\begin{abstract}
Abstrak:
Kepercayaan yang besar terhadap Pondok Modern Darussalam Gontor ditunjukkan oleh mas $\neg$ yarakat dengan datangnya ribuan calon pelajar dari seluruh Indonesia untuk men $\neg$ daf $\neg$ tar $\neg$ kan diri dan mengikuti ujian seleksi di Pondok Modern Darussalam Gontor. Materi Imla adalah salah satu materi yang diujikan dalam ujian masuk Pondok Modern Darussalam Gontor. Tujuan dari pengabdian ini adalah untuk membekali para pengajar untuk melaksakan bimbingan masuk Gontor. Bimago Yogyakarta adalah lembaga penyelenggara kursus persiapan calon santri Pondok Modern Darussalam Gontor. Bimago Yogyakarta bekerjasama dengan IKPM Yogayakarta mengadakan Pembekalan Metode Pengajaran Imla' Bagi Pengajar Bimago Yogyakarta. Metode yang digunakan dalam pengabdian masyarakat ini menggunakan workshop dengan tiga tahapan, pemaparan materi, praktek mengajar dan evaluasi. Hasil dari pengabdian masyarakat berupa penanaman dua metode self preparation methode dan student as observation object dalam pengajaran imla'.
\end{abstract}

Kata Kunci: Bimago, Imla' dan Pondok

\begin{abstract}
:
The Great trust in Pondok Modern Darussalam Gontor was shown by the community by the arrival of thousands of prospective students from all over Indonesia to register and take the selection exam at Pondok Modern Darussalam Gontor. Imla material is one of the materials in the entrance exam of Pondok Modern Darussalam Gontor. Bimago Yogyakarta is an institution that organized preparation courses for prospective students of Pondok Modern Darussalam Gontor. The purpose of this service is to equip teachers to carry out Gontor entrance guidance. Bimago Yogyakarta collaborated with IKPM Yogayakarta held a briefing for teachers on the Imla' Teaching Method. This community service is carried out using a workshop method with three stages, material presentation, teaching practice and evaluation. The results of community service is using two methods of self preparation method and student as observation object in teaching of imla' material.
\end{abstract}

Keywords: Bimago, Imla' and Boarding 


\section{PENDAHULUAN}

Bimbingan Masuk Gontor (Bimago) adalah program pendidikan yang ditujukan untuk memfasilitasi masyarakat atau calon pelajar yang ingin melanjutkan jenjang pendidikannya ke Kulliyatul Mu'allimin Al-Islamiyah (KMI) di Pondok Modern Darussalam Gontor. Bimbingan ini disajikan secara terstruktur sesuai dengan kebutuhan materi yang perlu dikuasai oleh calon pelajar. Bimbingan ini dikelola dan dilaksanakan oleh alumni Pondok Modern Darussalam Gontor Gontor baik perseorangan maupun kelompok yang telah terdaftar dan terstruktur di bawah arahan Ikatan Keluarga Pondok Modern (IKPM) Cabang di daerah masing-masing. Alasan didirikannya Bimago (atau yang sejenis) berawal dari dihapuskannya system pendidikan calon pelajar di Pondok Modern Darussalam Gontor (Amaliyah, 2019) .

Bimago dengan proses yang telah dijalaninya dari waktu ke waktu terus mengalami perbaikan dan penyempurnaan ke arah yang lebih baik sehingga dapat memberikan pelayanan yang optimal kepada masyarakat. Materi pengajaran hingga standar pelaksanaan pun telah diatur sedemikian rupa agar dapat meningkatkan efektifitas pelaksanaan bimbingan. Hal ini merupakan wujud tanggung jawab Pondok Modern Darussalam Gontor beserta para alumninya dalam memberikan kebermanfaatan dan pengabdian kepada masyarakat secara luas. Meskipun begitu, bimbingan ini tetap membutuhkan komitmen dari pihak-pihak terkait agar dapat berhasil seperti yang diharapkan mulai dari panitia pelaksana dalam hal memberikan pelayanan dan koordinasi kegiatan yang baik, orang tua calon pelajar dalam hal memberikan dorongan semangat bagi putra-putrinya, dan juga calon pelajar itu sendiri dalam hal menguatkan hati untuk masuk ke dalam Pondok Modern Darussalam Gontor.

Kepercayaan yang besar terhadap Pondok Modern Darussalam Gontor ditunjukkan oleh masyarakat dengan datangnya ribuan calon pelajar dari seluruh Indonesia untuk mendaftarkan diri dan mengikuti ujian seleksi di Pondok Modern Darussalam Gontor. Tentunya hal itu bukan upaya yang mudah karena selain harus menanggung biaya perjalanan dari daerah asal menuju Pondok Modern Darussalam Gontor, mereka pun dituntut mempersiapkan diri sebaik mungkin untuk bersaing dengan ribuan calon pelajar lainnya. Alasan ini didasari keinginan untuk lulus dan menjadi santri di Pondok Modern Darussalam Gontor.

Kepercayaan tersebut bukanlah tanpa alasan, mengingat Pondok Modern Darussalam Gontor adalah Lembaga Pendidikan Islam dengan sistem pengajaran modern yang telah lama berkiprah dalam dunia pendidikan ke-pesantrenan di Indonesia. Aspek kemodernan ini telah ada semenjak para Trimurti (para pendiri pondok pesantren) mendirikan para pesantren ini. Pesantren dijalankan dengan prinsip pendidikan yang terpadu dan totalitas selama 24 jam dalam lingkungan pendidikan yang representative (Joni \& others, 2016). Pondok Modern Darussalam Gontor tidak hanya memberikan bekal kepada para santrinya berupa ilmu agama saja, akan tetapi juga dilengkapi dengan berbagai pelatihan keterampilan hidup (lifeskill) yang berguna bagi kehidupannya di tengah masyarakat (Nurhakim, 2011). Sistem ini efektif dalam membentuk karakter santri sesuai dengan nilai-nilai yang diharapkan Pondok Modern Darussalam Gontor. Hal ini dibuktikan dengan banyaknya kiprah tokoh-tokoh nasional di Indonesia yang merupakan alumni Pondok Modern Darussalam Gontor. 
Pondok Modern Darussalam Gontor menerapkan ujian seleksi yang berbeda dari lembaga pendidikan pada umumnya, ada dua jenis ujian yang diselenggarakan yaitu ujian lisan (alimtihan al-syafahiy) dan ujian tulis (al imtihan al-tahririy). Ujian lisan meliputi materi baca AlQur'an, tajwid, ibadah amaliyah, ibadah qouliyah, hafalan do'a sehari-hari, hafalan surat-surat pendek, dan wawancara singkat. Sedangkan ujian tulis meliputi materi Bahasa Indonesia, berhitung soal, berhitung angka, dan imla' (dikte tulis Arab) (Maslul et al., 2020). Berbagai tuntutan materi inilah yang membuat peran dan fungsi Bimago dirasa cukup penting dalam menyiapkan calon pelajar menghadapi ujian masuk dan mengenalkan budaya pesantren.

Salah satu materi ujian yang kerap menghambat calon pelajar adalah materi imla' atau menulis arab. Keterampilan menulis Arab ini dapat dipelajari oleh calon pelajar melalui pengajaran imla' dengan dibimbing oleh ustadz/ustadzah. Imla' (dikte) adalah pengalihan suara dari huruf-huruf yang didengar dan dipahami ke dalam simbol-simbol tulis atau penataan huruf yang benar dan sesuai dalam sebuah kata yang dimaksud sehingga memunculkan keselarasan antara lafal dan makna (Ashoumi et al., 2020). Imla' merupakan salah satu cabang ilmu yang sangat penting dan tidak dapat dipisahkan dari cabang keilmuan Bahasa Arab lainnya. Karena penguasaan imla' yang baik akan memudahkan santri/pelajar dalam memahami bidang ilmu lainnya seperti nahwu, sharaf, ta'bir, hingga balaghah.

Pengajaran imla' di Bimago dilaksanakan melalui metode instruksi langsung. Pengajar menjelaskan tahapan materi secara sistematik kepada siswa. Dalam Imla' misalnya dieknal metode ikhtibari dalam penyampaiannya. Rathomi dengan mengutip Al-Ghali, bahwa metode ikhtibari adalah metode dimana guru menyiapkan teks yang mengandung kaidah penulisan Bahasa Arab, membacakannya kepada siswa, siswa mendengar dan menulis apa yang dibacakan pengajar tersebut, dan kemudian pengajar memeriksa hasil latihan siswa serta membahas kesalahan-kesalahan yang ditemukan (Rathomi, 2019). Disamping itu, kebiasaan membaca dapat berperan penting terhadap kemampuan berbicara, kebiasaan membaca adalah kegiatan membaca yang telah membudaya dalam suatu masyarakat dan yang perlu dicapai ialah kebiasaan membaca yang efesien, yaitu kebiasaan membaca yang disertai minat yang baik (Haryadi, 2020). Beberapa proses ini selain menuntut fokus dari para siswa juga menuntut pemahaman dan keterampilan yang mumpuni dari para pengajar selaku fasilitator pembelajaran.

Selain membutuhkan pemahaman yang komprehensif terhadap teori-teori imla' para pengajar juga dituntut untuk memiliki keterampilan-keterampilan yang penting dalam mengajarkan imla' di antaranya: kejelasan artikulasi (pengucapan tidak dilakukan terlalu cepat atau terlalu rendah, kejelasan makharijul huruf (kejelasan pengajar dalam mengucapkan perbedaan antara huruf satu dengan huruf yang lainnya), dan keterampilan menjelaskan materi maupun memberi petunjuk. Yumayyin menjelaskan setidaknya ada lima syarat yang harus diperhatikan pengajar imla' (JAUHARI, 2015), yaitu:

1. Teks yang diperdengarkan adalah teks-teks yang disesuaikan dengan perkembangan pelajar dan tidak membebani pelajar baik dari segi kognitif, afektif, maupun psikomotor;

2. Menghindari kesalahan dalam membaca atau memberikan teks bacaan; 
3. Memperhatikan tanda baca dan tidak tergesa-gesa;

4. Melakukan pengulangan bacaan sesuai tingkat kesulitan bacaan;

5. Bersuara keras dan jelas.

Beberapa hal tersebut membutuhkan persiapan yang matang dari para pengajar baik berupa pemahaman materi yang mendalam, kondisi fisik maupun mental, hingga pada hal-hal teknis yang mempengaruhi keberhasilan siswa dalam belajar. Maka dari itu, dibutuhkan pelatihan metode pengajaran imla' bagi para pengajar Bimago masuk Pondok Modern Darussalam Gontor.

\section{METODE}

Kegiatan pengabdian masyarakat ini menggunakan tiga tahapan. Pertama, penyampaian materi kepada para pengajar. Metode ini memfokuskan pada upaya mempersiapkan diri seorang pengajar. Hal ini tidak terlepas dari metode pengajaran imla yang bersegi satu. Pengajar menjadi titik pusat pembelajaran dalam rangka pengembangan ilmu pengetahuan dan teknologi (Sumiati, 2018). Hal ini dipengaruhi oleh empat sebab: peserta, Imla adalah pembelajaran bersegi satu dari pengajar kepada peserta didik. Kedua, materi yang disampaikan berfokus pada ucapan pengajar, bukan pihak lain bahkan seorang peserta didik sekalipun. Ketiga, pengajar harus memperlihatkan bentuk mulut dan wajah sebagaimana makhorijul huruf dari setiap huruf hijaiyah. Keempat, pengajar harus tepat dalam penyampaian instruksi kepada peserta didik.

Kedua, praktik dari para pengajar dalam menyampaikan materi Imla. Hal ini untuk mengetahui ukuran pemahaman para pengajar. Selain itu, juga untuk mengetahui praktek mengajar dari para pengajar Imla. Ketiga, evaluasi. Pada tahapan terakhir ini adalah penyampaian hasil dari pembekalan. Hasil evaluasi untuk dijadikan dasar dari pembekalan berikutnya.

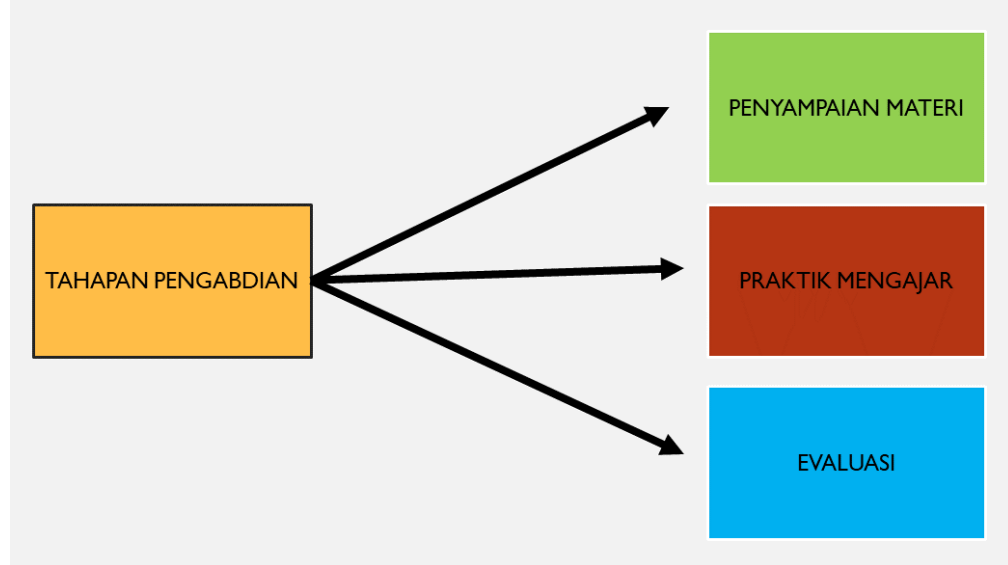

Gambar 1. Kerangka Pelaksanaan Pengabdian Masyarakat

\section{HASIL DAN PEMBAHASAN}


Tahapan pertama adalah penyampaian materi kepada para pengajar. Materi pembekalan dalam pengabdian ini terbagi menjadi dua. Pertama, self preparation methode. Metode ini adalah metode persiapan untuk pengajar. Pengajar diharapkan telah siap menyampaikan materi kepada calon pelajar. Sehingga, materi dapat diterima dengan maksimal oleh calon pelajar. Kedua, student as observation object. Bagian kedua adalah bagian pembekalan atau pengabdian ini adalah upaya untuk membekali pengajar untuk mampu mengobervasi calon pelajar untuk selanjutnya sebagai bahan acauan pengajaran berikutnya.

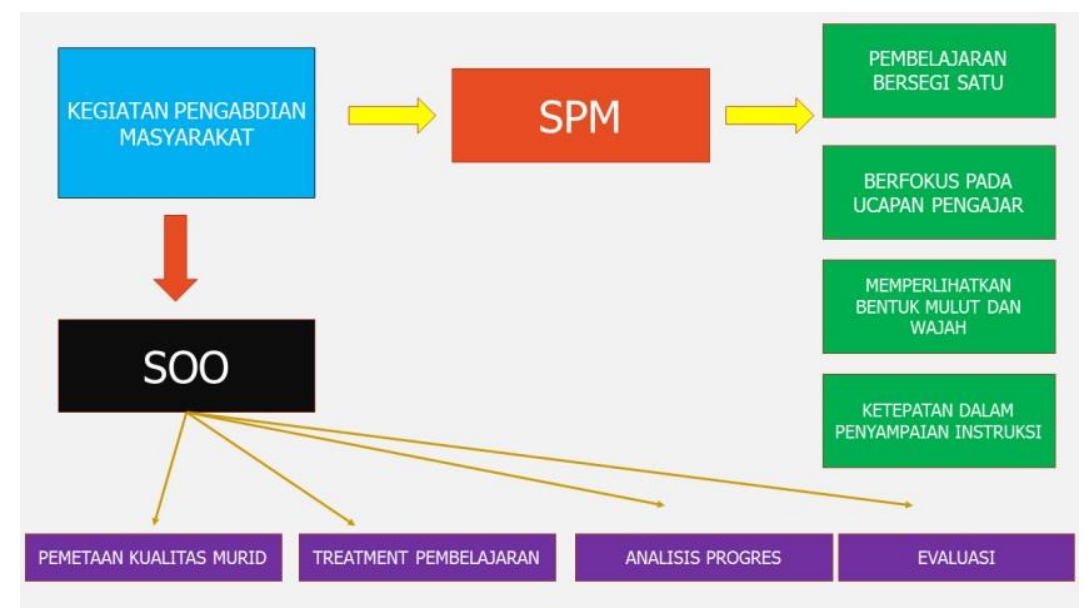

Gambar 2: Materi Pembekalan

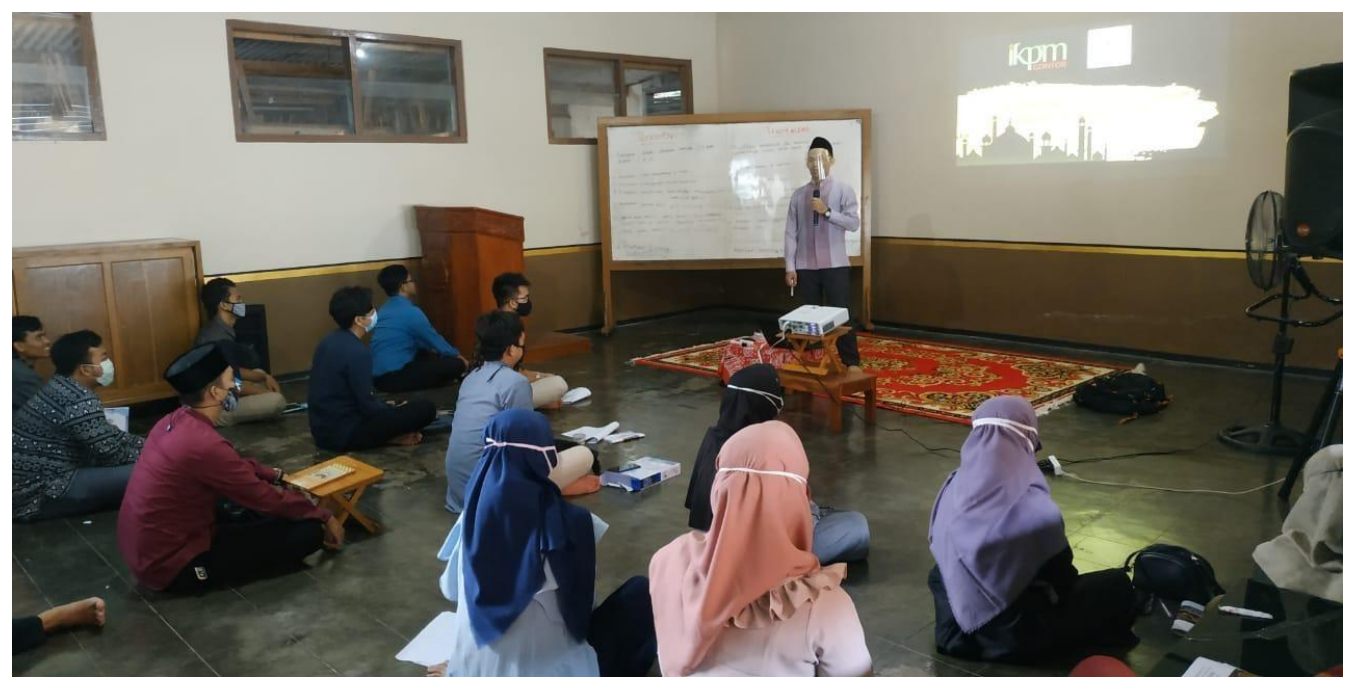

Gambar 3: Penyampaian Materi

Tahapan Kedua, praktek dari pengajar. Praktek ini adalah tahapan kedua dalam pembekalan. Para pengajar diminta untuk praktek mengajar imla'. Dengan kata lain, pengajar diminta untuk learning by doing. Praktek ini penting untuk melihat dan menganalisis bagaimana penerimaan materi para pengajar.

Para pengajar terpilih diminta untuk maju ke depan. Pemateri memberikan beberapa 
contoh naskah dalam Bahasa arab yang akan dibacakan sebagai materi praktek. Para peserta lainnya berperan sebagai peserta didik. Hasil dari praktek akan dievaluasi dan diberikan catatan.

Tahapan ketiga, adalah evaluasi. Para pengajar imla' diminta untuk memberikan evaluasi atas pembekalan. Selama pembekalan pasti ada hal-hal yang dirasa belum dipahami ataupun adanya ketidak jelasan.

Evaluasi diberikan secara langsung untuk masukan. Selain itu, evaluasi dijadikan feedback positif untuk diberikan tindak lanjut pada pembekalan lainnya. Evaluasi dilakukan dengan menuliskan berbagai tanggapan soal pembekalan.

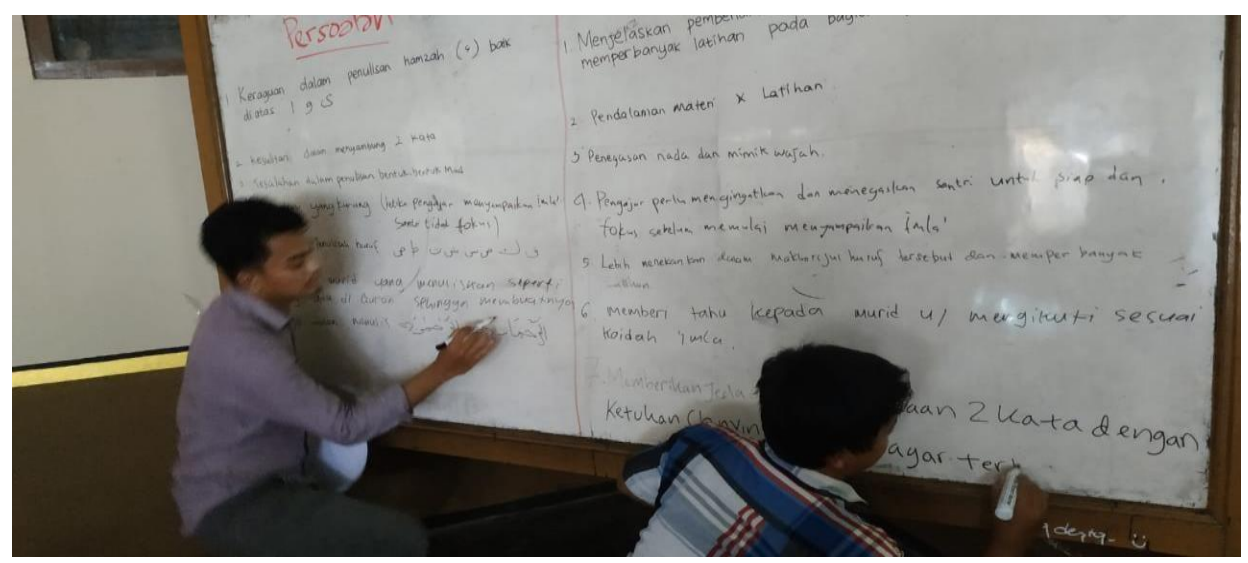

Gambar 4: Evaluasi

\section{SIMPULAN}

Dari pengabdian ini dapat disimpulkan bahwa pengabdian ini menggunakan tiga tahapan. Pertama penyampaian materi, kedua praktek mengajar para pengajar dan ketiga evaluasi. Dalam penyampaian materi, ada dua materi yang disampaikan, yaitu self preparation methode dan student as observation object dalam pengajaran imla' yang ada di Gontor

\section{UCAPAN TERIMA KASIH}

Ucapan terima kasih ini disampaikan kepada IKPM Yogyakarta yang telah menunjuk dan memberikan kesempatan kepada penulis dan jajaran pemateri pengabdian di Bimago Yogyakarta. Semoga dengan terselenggaranya pengabdian ini dapat meningkatkan kualitas para pengajar imla' serta dapat membantu para calon pelajar masuk Pondok Modern Darussalam Gontor.

\section{REFERENSI}

Amaliyah, D. A. (2019). Pola komunikasi pembimbing dalam penguatan mental anggota bimbingan belajar Simulasi Gontor (Sigor): studi deskriptif pada bimbingan belajar Simulasi Gontor Di Surabaya. UIN Sunan Ampel Surabaya.

Ashoumi, H., Chotimah, C., Zulfah, M. A., Rahmawati, R., \& others. (2020). Pelatihan Metode Pembelajaran Mind Mapping Bagi Guru Mata Pelajaran di MI Darul Ma'arif. 
Jumat Pendidikan: Jurnal Pengabdian Masyarakat, 1(1), 1-6.

Haryadi, R. N. (2020). Pengaruh PENGARUH KEBIASAAN MEMBACA TERHADAP

KEMAMPUAN BERBICARA BAHASA INGGRIS SMA Negeri 99 Jakarta. Jurnal

Manajemen Bisnis dan Keuangan, 1(2), 14-30.

JAUHARI, H. Q. A. (2015). Pembelajaran Qowaid Al-Imlak Di Jurusan Pendidikan Bahasa Arab (PBA) UIN Maulana Malik Ibrahim Malang. Prosiding Konferensi Nasional Bahasa Arab, 1(1).

Joni, S., \& others. (2016). Eksistensi dan Kontribusi Pondok Modern Darussalam Gontor Dalam Pembangunan Sumber Daya Manusia. At-Ta'dib, 11(2), 201-226.

Maslul, S., Thonthowi, T., Fithroni, F., \& Sadewa, A. (2020). Pelatihan Baca Al-Qur'an dan Pendampingan Calon Santri Pondok Modern Darussalam Gontor di Masa Covid-19. Jurnal Pemberdayaan: Publikasi Hasil Pengabdian Kepada Masyarakat, 4(3), 347354.

Nurhakim, M. (2011). Imam Zarkasyi dan pembaharuan pesantren: Rekonstruksi aspek kurikulum, menejemen dan etika pendidikan. Progresiva, 5(1), 162206.

Rathomi, A. (2019). IMLA' MANZHUR DALAM PEMBELAJARAN BAHASA ARAB PADA SISWA SEKOLAH DASAR. PrimEarly: Jurnal Kajian Pendidikan Dasar Dan Anak Usia Dini, 2(1).

Sumiati, S. (2018). Peranan Guru Kelas Dalam Meningkatkan Motivasi Belajar Siswa. TARBAWI: Jurnal Pendidikan Agama Islam, 3(02), 145-164. 